\title{
Primary Liver Large B-Cell Lymphoma: A Rare Diagnosis
}

\author{
Joana de Castro Rocha1, Raquel Lopes², Ana Rita Cruz¹, Cristina Gonçalves², \\ João Araújo Correia1, Jorge Coutinho² \\ ${ }^{1}$ Internal Medicine Department, Centro Hospitalar do Porto, Porto, Portugal \\ ${ }^{2}$ Hematology Department, Centro Hospitalar do Porto, Porto, Portugal \\ Email: joanadecastro.r@gmail.com
}

Received 23 February 2015; accepted 8 March 2015; published 12 March 2015

Copyright (C) 2015 by authors and Scientific Research Publishing Inc.

This work is licensed under the Creative Commons Attribution International License (CC BY). http://creativecommons.org/licenses/by/4.0/

(c) (i) Open Access

\begin{abstract}
Primary liver lymphoma is extremely rare, in most of cases it is a B cell lymphoma. Usually the diagnosis is made in middle-aged individuals and most of them have a relatively short life expectancy. In this article, the authors present a case report of a 75-year-old woman with symptoms of three weeks of evolution of diffuse abdominal pain, asthenia and anorexia. The analysis showed cyto cholestasis and the radiological image with lush hepatomegaly because of a large hepatic mass. The patient started chemotherapy and actually is well twenty months after the end of the chemotherapy.
\end{abstract}

\section{Keywords}

\section{Large B Cell Lymphoma, Liver, Rarity}

\section{Introduction}

Primary liver lymphoma has high rarity diagnosis [1]-[6], corresponding to less than "1\%" of all lymphomas [7]-[9]. It acounts approximately for "0.4\%" [10] [11] of the extranodal non-Hodgkin lymphomas and approximately " $0.01 \%$ " to " $0.06 \%$ " [1] [2] [6] [7] [12] of the non-Hodgkin lymphomas.

The mean age of presentation is around 50 years and the median survival is between 8 and 16 months [3], depending on response to treatment. It has predominance of males and white individuals [13].

The form of presentation could be very variable and nonspecific and it could delay the diagnosis [7]. B symptoms, hepatomegaly, abdominal pain and cholestatic jaundice are the most common forms of presentation. The diffuse liver infiltration and acute hepatic insufficiency are even more rare forms of manifestation of the disease [8]. 
According to some authors, the primary non-Hodgkin lymphoma could be classified as nodular and diffuse and this last one has a worse prognosis [9].

The histology is the gold standard to make the diagnosis.

The small number of reported cases in the literature, the prognosis and treatment considered optimal still continues on study [9] [12].

\section{Case Report}

The authors expose a case of a 75-year-old woman, previously autonomous, with known history of arterial hypertension and iatrogenic hypothyroidism that went to the hospital with diffuse abdominal pain, asthenia and anorexia with three weeks of evolution. In admission she was in degraded general state with third part dependence for daily life activities, with temporal and spatial disorientation and an ECOG of 3. She complained of abdominal pain preferably located on the right hypochondrium. The analysis showed a proeminent cyto cholestasis (TGO three times higher, TGP 1.5 times higher, AF 9 to 10 times higher, and GGT 22 times higher), total bilirubin higher (3.99 mg/dl), hypoalbuminemia $(2.78 \mathrm{~g} / \mathrm{dl})$. The full blood count showed leukocytosis $(13.35 \times$ $\left.10^{3} / \mu \mathrm{l}\right)$, neutrophylia $\left(11.51 \times 10^{3} / \mu \mathrm{l}\right)$, hemoglobin $(10.7 \mathrm{~g} / \mathrm{dl})$ and platelets $\left(288 \times 10^{3} / \mu \mathrm{l}\right)$. The reactive C protein was $180.7 \mathrm{mg} / \mathrm{l}$. The abdominal ultrasound described a nodular lesion of large dimensions occupying almost the entire liver of a nonspecific characteristic. She did a thoracic abdominal and pelvic computed tomography showing a massive hepatomegaly with $23 \mathrm{~cm}$ diameter by a large mass of about $19 \mathrm{~cm}$ occupying a significant part of the liver with a relative central location in almost every segments of the left lateral lobe and VI segment, involving also the remaining liver with enhancement in the arterial phase overall hypodense relative to hepatic parenchyma in venous and delayed phases, with extensive area of central necrosis, which lead to compression of the biliary tree and dilation of intrahepatic branches (Figure 1). There was no personal history of cancer neither autoimmune disease.

In the remaining study, it was excluded HIV, HVC and HVB infections, and immune study was also normal and blood cultures were negative. There was a positive tumor marker alfa-fetoprotein $(0.5 \mu \mathrm{g} / \mathrm{L})$. The histology of the liver biopsy performed with ultrasound control revealed that it was diffuse large B cell lymphoma. Cra-
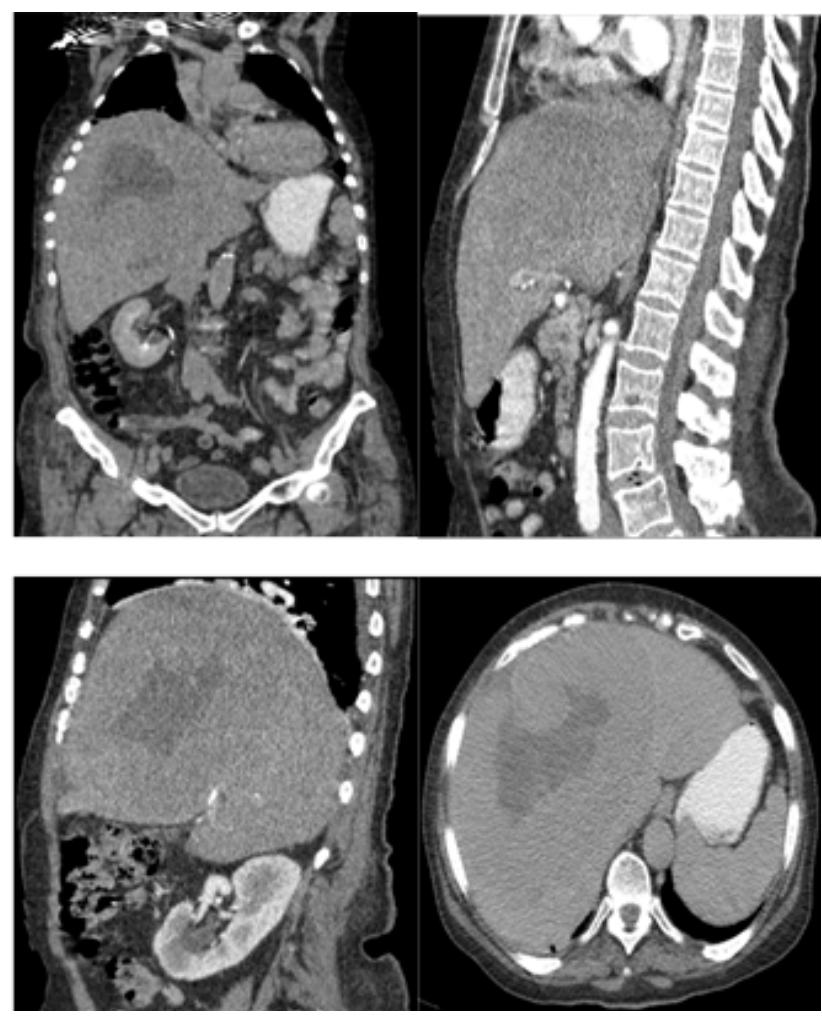

Figure 1. Thoracic abdominal and pelvic computed tomography. 
neoencefalic computed tomography had no lesions. The bone marrow aspiration and biopsy revealed no lymphoma involvement.

The patient directed began treatment with chemotherapy regimen with CVP (Cyclophosphamide, Vincristine, Prednisolone) and because of the evidence of improvement it was changed to CNOP (Cyclophosphamide, Mitoxantoma, Vincristine, Prednisolone).

After de $4^{\text {th }}$ and $8^{\text {th }}$ chemotherapy cycles, the images of computed tomography were repeated and it was found that there was a gradual reduction of the hepatic lesion $(30.0 \mathrm{~mm} \times 57.1 \mathrm{~mm}$ and $17.0 \mathrm{~mm} \times 45.1 \mathrm{~mm}$ ) (Figure 2 and Figure 3).

\section{Conclusions}

The primary hepatic lymphoma presents with hepatic invasive behavior, and may present diffuse involvement. It is a very rare disease of unknown etiology, although studies points to be related to viral infection with HVB or HVC [1], but in this case there were negative.

The atypical clinical signs such as abdominal pain which is located in the right hypochondrium, lead to ask for imaging exams. The finding of a hepatic lesion with a central necrotic area is the form of image presentation described in the literature to the primary hepatic lymphoma. In this case, there was a diffuse hepatic involvement.

The histology confirmed the diagnosis and it was decided to treat the patient with CVP. She presented a great clinical and analytical improvement after the first cycle.

The primary liver large B cell lymphoma is a rare pathology with some cases documented in the literature. With a suspicious imaging finding, the liver biopsy should be done to establish a diagnosis and providing targeted treatment, which can be instrumental in improving the quality of life of the patients. Just as our case, and beside poor prognosis and short survival time, it is possible to provide an improvement in the general state life having a possibility of cure.
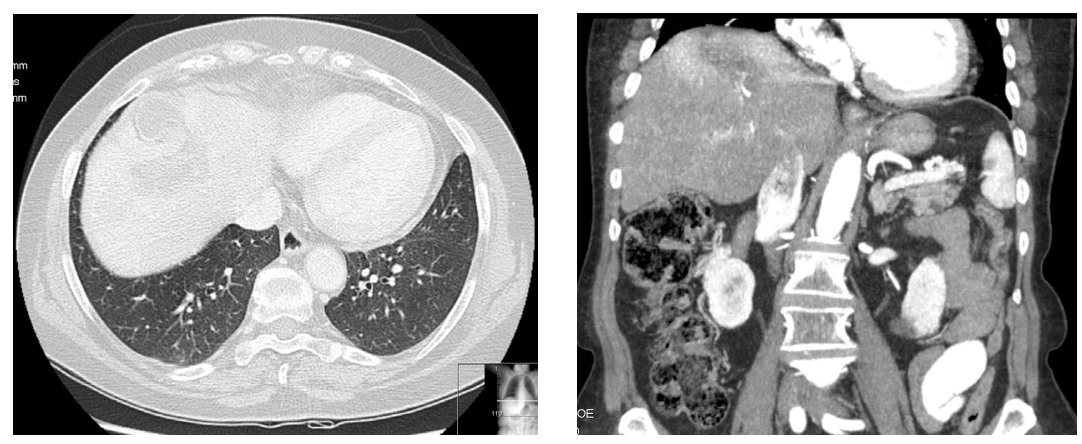

Figure 2. Computed tomography after 4 cycles of chemotherapy.

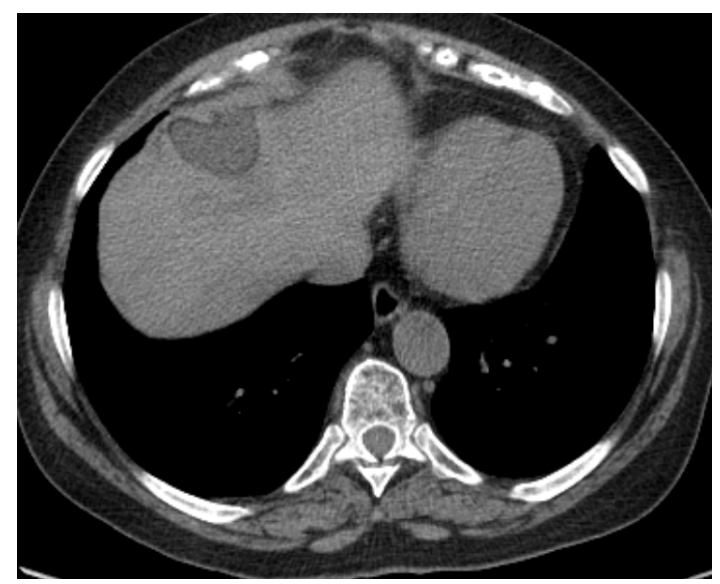

Figure 3. Computed tomography after 8 cycles of chemotherapy. 
Given the poor condition of the patient and low ECOG score, it was decided for CVP. As she had good evolution with this treatment it was decided to switch to CNOP.

Note: This article was recommended and approved by Forum Hematológico do Norte.

\section{References}

[1] Mouna, B., Wafae, A., Hind, M. and Hassan, E. (2011) Primary Liver Lymphoma: A Case Report and Literature Review. Journal of Cancer Therapy, 2, 725-727. http://dx.doi.org/10.4236/jct.2011.25098

[2] Leung, V., Lin, S.Y., Loke, T., Chau, T.N., Leung, C.Y., Fung, T.P. and Lam, S.H. (2009) Primary Hepatic Peripheral T-Cell Lymphoma in a Patient with Chronic Hepatitis B Infection. Hong Kong Medical Journal, 15, 288-290.

[3] Zafar, M.H., Aggarwal, S. and Bhalla, S. (2012) Complete Response to Chemotherapy in Primary Hepatic Lymphoma. Journal of Cancer Research and Therapeutics, 8, 114-116. http://dx.doi.org/10.4103/0973-1482.95187

[4] Stancu, M., Jones, D., Veja, F. and Medeiros, L.J. (2012) Peripheral T-Cell Lymphoma Arising in the Liver. American Journal of Clinical Pathology, 118, 574-581.

[5] Varshney, P., Arya, R. and Songra, B. (2014) Primary Non Hodgkin Lymphoma of Liver: A Rare Diagnosis. Journal of Medical Science and Clinical Research, 2, 398-401.

[6] Ma, Y.J., Chen, E.Q., Chen, X.B., Wang, J. and Tang, H. (2011) Primary Hepatic Diffuse Large B Cell Lymphoma: A Case Report. Hepatitis Monthly, 11, 203-205.

[7] Mishra, S., Shukla, A., Tripathi, A.K. and Kumar, A. (2012) Primary T-Cell Lymphoma of Liver. BMJ Case Reports, 2013. http://dx.doi.org/10.1136/bcr-2012-008467

[8] Haider, F.S., Smith, R. and Khan, S. (2008) Primary Hepatic Lymphoma Presenting as Fulminant Hepatic Failure with Hyperferritinemia: A Case Report. Journal of Medical Case Reports, 2, 279. http://dx.doi.org/10.1186/1752-1947-2-279

[9] Emile, J.F., Azoulay, D., Gornet, J.M., Lopes, G., Delvart, V., Samuel, D., Reynes, M., Bismuth, H. and Goldwasser, F. (2001) Primary Non-Hodgkin's Lymphomas of the Liver with Nodular Diffuse Infiltration Patterns Have Different Prognoses. Annals of Oncology, 12, 1005-1010. http://dx.doi.org/10.1023/A:1011131930409

[10] Ehsan, N., Badr, M.T., El-Refaie, A. and Attar, I.E. (2010) Diffuse Large B Cell Lymphoma of the Liver: Immunophenotypic Profile, Biological Properties and Association with Hepatitis C Virus Infection. Nile Liver Journal, 1, 43-48.

[11] Bouliaris, K., Christodoulidis, G., Koukoulis, G., Mamaloudis, I., Ioannou, M., Bouronikou, E., Palassopoulou, M. and Tepetes, K. (2014) A Primary Hepatic Lymphoma Treated with Liver Resection and Chemotherapy. Case Reports in Surgery, 2014, Article ID: 749509.

[12] Resende, V., Oliveira, T.S., Gomes, R.T., Laboissiére, R.S., Tavares Jr., W.C. and Couto, O.F.M. (2013) Primary Hepatic Lymphoma: A Case Report. International Journal of Surgery Case Reports, 4, 1165-1168. http://dx.doi.org/10.1016/j.ijscr.2013.10.003

[13] Sousa, M.H. and Albuquerque, A. (1999) Linfoma primário do fígado. Relato de um caso clínico e revisão da literatura. Revista da Sociedade Portuguesa de Medicina Interna, 6, 122-127. 